\title{
PRINCIPIO DE LA RELATIVIDAD DE LA SENTENCIA
}

\author{
PRINCIPLE OF THE RELATIVITY OF THE JUDGMENT
}

\author{
Sait Francisco García-Osorio ${ }^{1}$ (D) . \\ 1. Universidad Juárez Autónoma de Tabasco. México. lic_sait@hotmail.com \\ *Correspondencia del Autor: Sait Francisco García-Osorio, correo electrónico: lic_sait@hotmail.com.
}

\section{RESUMEN}

Los primeros antecedentes del principio de la relatividad en México son encontrados en un proyecto para la Constitución del Estado de Yucatán en 1840 por el jurisconsulto Manuel Crescencio Rejón en donde se introduce un sistema que permite el control de la constitucionalidad lato sensu (a todo acto considerado constitucional) por los órganos judiciales utilizando por primera vez el término "amparar" cuando por resolución se anulaba una actividad que era contraria a la Constitución. Por ello, este documento otorga al lector un bosquejo respecto al principio de relatividad y declaratorio general de inconstitucionalidad el cual expone elementos a considerar para la buena administración de justicia en el estado mexicano.

Palabras clave: amparo; declaratorio general; fórmula Otero; juicio; sentencia.

Cómo citar:

García-Osorio, Sait Francisco. (2020). PRINCIPIO DE LA RELATIVIDAD DE LA SENTENCIA. Revista de Investigaciones Universidad del Quindio, 32(2), 16-25. https://doi.org/10.33975/riuq. $\underline{\operatorname{vol} 32 \mathrm{n} 2.516}$ 


\begin{abstract}
The first antecedents of the principle of relativity in Mexico are found in a project for the Constitution of the State of Yucatán in 1840 by the jurisconsult Manuel Crescencio Rejón where a system is introduced that allows the control of the constitutionality lato sensu (to all acts considered constitutional law) by judicial bodies using for the first time the term "protect" when an activity that was contrary to the Constitution was annulled by resolution. Therefore, this document provides the reader with an outline regarding the principle of relativity and general declaration of unconstitutionality, which sets out elements to consider for the good administration of justice in the Mexican state.
\end{abstract}

Keywords: amparo; general declaration; Otero formula; trial; sentence.

\section{INTRODUCCIÓN}

\section{¿Conoces la Fórmula Otero?}

El juicio de amparo es una las instituciones jurídicas más importantes del derecho mexicano, pues su objetivo es la defensa y protección de los derechos y libertades de los gobernados.

Es el elemento de balance que prevé la Constitución en favor de los ciudadanos (Fernández \& Samaniego, 2011) para que exista un equilibrio que no permita actuaciones arbitrarias en la relación de supra a subordinación entre ellos y el Estado. Permite a los gobernados impugnar y someter a un análisis constitucional aquellos actos de autoridad que consideren les causa un perjuicio y, en caso de que un juez competente los califique contrarios al texto constitucional, la sentencia puede destruir sus efectos. Como todos los procesos judiciales, el juicio de amparo se rige por reglas y principios que generan certeza y dan orden al actuar tanto del juez como de los gobernados.
Aunque algunos han sufrido ciertas modificaciones para ampliar el espectro de protección a raíz de la reforma constitucional en materia de derechos humanos, existen otros como el PRINCIPIO DE RELATIVIDAD DE LAS SENTENCIAS (FÓRMULA OTERO) que a pesar de haber sido matizado sigue influyendo en la psique de muchos jueces de la misma manera que en 1857 (Burgoa, 1999). Este principio tuvo un gran impacto en la vida jurídica de México y es uno de los pilares fundamentales en el Juicio de Amparo, es por ello que para todos los interesados en estudiar la carrera de derecho y para los ciudadanos que recurren al Juicio de Amparo es un deber conocer más sobre él.

\section{METODOLOGÍA}

La relatividad de las sentencias de amparo es uno de los principios implementados desde la fundación del juicio de garantías, el cual forma parte del sistema de control constitucional concentrado ejercido por un órgano jurisdiccional en México. En ese sentido, este trabajo de investigación 
se describe lo concerniente al Principio de la Relatividad de la Sentencia también denominado "Fórmula Otero" en honor de su creador, el ilustre jalisciense Mariano Otero. Se analiza su concepto, fundamento jurídico y su aplicación actual.

\section{RESULTADOS}

\section{Concepto}

El principio de relatividad de los efectos de la sentencia de amparo en México, según la Suprema Corte de Justicia de la Nación, se refiere a que las sentencias sólo se ocuparán de las personas físicas o morales que lo solicitan, limitándose a protegerlos sin hacer declaraciones sobre la ley o acto que lo motivare: dicha sentencia no beneficiará a nadie más, ni afectará a nadie más que la autoridad responsable y/o ejecutora (Ley de Amparo, Artículo 73). Este principio deriva del primer párrafo de la fracción II, del artículo 107 constitucional, que dispone:

“...Artículo 107. Todas las controversias de que habla el artículo 103 se sujetarán a los procedimientos y formas del orden jurídico que determine la ley, de acuerdo con las bases siguientes: [...] II. La sentencia será siempre tal, que sólo se ocupe de individuos particulares, limitándose a ampararlos y protegerlos en el caso especial sobre el que verse la queja, sin hacer una declaración general respecto de la ley o acto que la motivare [...]."
Derivado de la norma suprema la Ley de Amparo, en específico el artículo 73 señala lo siguiente:

“...Artículo 73. Las sentencias que se pronuncien en los juicios de amparo sólo se ocuparán de los individuos particulares o de las personas morales, privadas $u$ oficiales que lo hubieren solicitado, limitándose a ampararlos y protegerlos, si procediere, en el caso especial sobre el que verse la demanda [...]."

De lo anterior, se desprende que las sentencias protegerán al individuo (quejoso) que interponga un amparo en contra de un acto o ley, es decir, el amparo protege de manera individual a quien se queje y no a la colectividad. Nuestros Tribunales Colegiados de Circuito; han determinado que el principio de relatividad en las sentencias

"Evita que el Poder Judicial Federal invada las funciones del Legislativo al declarar inconstitucional una ley; de esta manera, el principio en comento obliga al tribunal de amparo a emitir la declaración de inconstitucionalidad del acto en forma indirecta y con relación a los agravios que tal acto cause a un particular, sin ejercer una función que no le corresponde. En otras palabras, la ley que rige el acto reputado violatorio 
de garantías, no se anula por el órgano de control mediante una declaración general, sino que se invalida su aplicación en cada caso concreto, respecto de la autoridad que hubiese figurado como responsable $y$ del individuo que haya solicitado la protección federal." (Tribunales Colegiados de Circuito, 1989).

Por su parte, el Pleno de nuestra Suprema Corte de Justicia de la Nación, establece que

"La sentencia que otorgue el amparo tiene un alcance relativo en la medida en que sólo se limitará a proteger al quejoso que haya promovido el juicio de amparo. Sin embargo, este principio no puede entenderse al grado de considerar que una sentencia que otorgue el amparo contra una ley sólo protegerá al quejoso respecto del acto de aplicación que de la misma se haya reclamado en el juicio, pues ello atentaría contra la naturaleza y finalidad del amparo contra leyes." (Pleno. Novena Época, 2011).

Los efectos de una sentencia que otorga la protección del amparo al peticionario (en materia de amparo contra leyes, de acuerdo con el Pleno de la Suprema Corte de Justicia de la Nación, son:

"Los de proteger exclusivamente al quejoso, pero no sólo contra el acto de aplicación con motivo del cual se haya reclamado la ley, si se impugnó como heteroaplicativa, sino también como en las leyes autoaplicativas, la de ampararlo para que esa ley no le sea aplicada válidamente al particular en el futuro" (Pleno. Novena Época, 2011).

El principio de relatividad de las sentencias de amparo, llamado también "fórmula Otero"...

“...constriñe, como claramente se advierte, el efecto de la sentencia que conceda la protección de la justicia federal solicitada, al quejoso, de manera que quien no haya sido expresamente amparado no puede beneficiarse con la apreciación que acerca de la inconstitucionalidad del acto reclamado haya expresado el juzgador en la mencionada sentencia; es decir, que quien no haya acudido al juicio de garantías, ni, por lo mismo, haya sido amparado contra determinados ley o acto, 
está obligado a acatarlos no obstante que dichos ley o acto hayan sido estimados contrarios a la Carta Magna en un juicio en el que aquél no fue parte quejosa" (Diccionario jurídico, 2020).

El principio de relatividad de las sentencias de amparo, también denominada Fórmula Otero consiste en que el efecto de la sentencia solo beneficiará al promovente, en consecuencia aquellos individuos que no participan como quejosos en la demanda de amparo, no serán protegidos por la decisión del tribunal en relación a la inconstitucionalidad (Fix-Zamudio, 1993) del acto reclamado, por lo que quien no haya acudido al juicio de garantías que se tramitó contra una ley o acto, tendrá la obligación de acatar la órdenes aunque las considere inconstitucionales, a pesar de que se haya comprobado en un amparo anterior otorgados otro individuo.

Atendiendo al principio de relatividad la sentencia que se dicte en el juicio de garantías no tendrá efectos generales, ya que sólo protege a quien solicitó el amparo y de ninguna manera a quien, por negligencia, falta de asesoría, situación económica precaria o cualquier otro motivo, no hiciere la reclamación en la vía constitucional.

\section{Fundamento jurídico del principio de la relatividad de las sentencias.}

La base constitucional del principio de Relatividad o Fórmula Otero se encuentra en la fracción II del artículo 107 Constitucional el cual indica textualmente que "la sentencia será siempre tal, que sólo se ocupe de individuos particulares, limitándose a ampararlos y protegerlos en el caso especial sobre el que verse la queja, sin hacer una declaración general respecto de la ley o acto que la motivare".

Por su parte, la Ley de Amparo en su artículo 76 y refiriéndose a las sentencias que se pronuncien indica que, sólo se ocuparan de los individuos particulares o de las personas morales, privadas u oficiales que lo hubiesen solicitado, limitándose a ampararlos y protegerlos, si procediere, en el caso especial sobre el que verse la demanda, sin hacer una declaración general respecto de la Ley o acto que la motivare.

\section{Declaratoria general de inconstitucionalidad}

Mediante la reforma constitucional aprobada por el Poder Reformador de la Constitución en materia de Amparo, publicada en el Diario Oficial de la Federación el 6 de junio de 2011, se integró en el sistema jurídico mexicano la figura de la declaratoria general de inconstitucionalidad. A la luz de dichos lineamientos, mediante el decreto publicado el día 2 de abril de 2013, el legislador ordinario derogó la Ley de Amparo de 1936 y, en su lugar, expidió una nueva. Esta nueva legislación de amparo establece y regula en los artículos comprendidos del 231 al 235 la figura de declaratorio general de inconstitucionalidad.

Ladeclaratoriageneraldeinconstitucionalidad es un mecanismo de control directo de la constitucionalidad; es decir, esta figura tiene por efecto que el Tribunal Pleno de la Suprema Corte de Justicia de la Nación haga un análisis en abstracto de la constitucionalidad de una 
norma general y, así, determine su invalidez si se reúnen por lo menos 8 votos de los ministros integrantes - tal como acontece en la acción de inconstitucionalidad-.

Así, de determinarse la invalidez de una norma general mediante la declaratoria general, el efecto será privar de vigencia —no así derogar- la norma declarada inconstitucional.

Por virtud de lo aquí expuesto, la declaratoria general de inconstitucionalidad no otorga efectos generales a los juicios de amparo indirectos en revisión en los que se ha determinado la inconstitucionalidad de una norma general, sino que es un medio de control de la constitucionalidad de normas totalmente independiente del juicio de amparo. Ahora, es cierto también que se condiciona el ejercicio de este mecanismo a que existan juicios de amparo resueltos con anterioridad, tal como se verá adelante, más ello no quiere decir que la declaratoria de marras otorgará efectos erga omnes a lo determinado dentro de un juicio de amparo.

Dicho eso, la Ley de Amparo indebidamente regula dentro de su capítulo correspondiente para la declaratoria general de inconstitucionalidad dos supuestos distintos, de los cuales sólo uno de ellos puede derivar en una declaratoria general, a saber:

i. Cuando el Pleno y las Salas de la Suprema Corte resuelvan la inconstitucionalidad de una norma general al resolver por dos ocasiones un amparo indirecto en revisión.

En este caso en particular, el presidente de la Sala o de la Suprema Corte, según sea el caso, informará a la autoridad emisora de la norma sobre el resultado de las resoluciones emitidas; no obstante, esta figura es letra muerta, pues no se establece para efectos de qué se hace con dicha notificación ni qué pasa si la autoridad emisora es omisa en modificar de modo alguno la norma declarada inconstitucional.

De este modo demostramos que es impreciso que esta facultad de notificación por parte de la Corte sea regulada en el capítulo de la Ley de Amparo relativa a la declaratoria general de inconstitucionalidad, pues la misma no tiene por efecto analizar en abstracto y determinar con efectos erga omnes la inconstitucionalidad de una norma general.

ii. Cuando el Pleno o las Salas del Máximo Tribunal o los Tribunales Colegiadosestablezcanjurisprudencia por reiteración en tal sentido al resolver sobre la inconstitucionalidad de normas en amparo indirecto en revisión, supuestos que dan origen a la procedencia de la declaratoria general de inconstitucionalidad en los términos que se señalarán a continuación.

En esto es conveniente aclarar que la jurisprudencia que sea emitida, ya sea por el Alto Tribunal o dentro de un Circuito, necesariamente debe derivarse de amparos indirectos en revisión. Es decir, no es factible obtener una declaratoria de esta índole al resolverse ante un Juez de Distrito un amparo indirecto o cuando un Tribunal Colegiado, o, inclusive, la Suprema Corte, resuelva sobre amparos directos o, en su caso, el recurso de revisión sobre estos últimos. 
Para la procedencia de la declaratoria general de inconstitucionalidad, el artículo 107, fracción II, tercer párrafo, de la Constitución General, establece con claridad que el único tipo de jurisprudencia que podrá ser tomada en consideración para el efecto de la procedencia de la declaratoria general es aquella que esté conformada por reiteración, veamos:

“...Artículo 107, fracción II, tercer párrafo. - Cuando los órganos del Poder Judicial de la Federación establezcan jurisprudencia por reiteración en la cual se determine la inconstitucionalidad de una norma general, la Suprema Corte de Justicia de la Nación lo notificará a la autoridad emisora. Transcurrido el plazo de 90 dias naturales sin que se supere el problema de inconstitucionalidad, la Suprema Corte de Justicia de la Nación emitirá, siempre que fuere aprobada por una mayoría de cuando menos ocho votos, la declaratoria general de inconstitucionalidad, en la cual se fijarán sus alcances $y$ condiciones en los términos de la ley reglamentaria..."

Enese entendido,únicamentelajurisprudencia por reiteración, creada por los Tribunales Colegiados de Circuito, las Salas y el Pleno de la Suprema Corte al resolver las revisiones de amparos indirectos, será la aplicable para la procedencia de una declaratoria erga omnes, y no así la jurisprudencia que en contradicción sea establecida por los Plenos de Circuito o la Corte.

Continuando en el análisis de la figura de la declaratoria general de inconstitucionalidad, vemos que ésta sólo podrá ser efectuada por el Pleno de la Suprema Corte siempre que se hubieren satisfecho dos requisitos; el primero de ellos consiste en la existencia de la jurisprudencia en los términos establecidos por el artículo 232 de la Ley de Amparo, tratándose de las Salas y el Pleno de la Corte, así como en términos del arábigo 233 de la ley en comento, tratándose de Tribunales Colegiados y el Pleno de Circuito correspondiente cuándo éstos lo hubieren solicitado a la Corte, veamos:

“...Artículo 232, primer párrafo. - Cuando el pleno o las salas de la Suprema Corte de Justicia de la Nación, en los juicios de amparo indirecto en revisión, establezcan jurisprudencia por reiteración, en la cual se determine la inconstitucionalidad de la misma norma general, se procederá a la notificación a que serefiere el tercerpárrafo de la fracción II del artículo 107 de la Constitución Política de los Estados Unidos Mexicanos..." 
“...Artículo 233.- Los plenos de circuito, conforme a los acuerdos generales que emita la Suprema Corte de Justicia de la Nación, podrán solicitar a ésta, por mayoría de sus integrantes, que inicie el procedimiento de declaratoria general de inconstitucionalidad cuando dentro de su circuito se haya emitido jurisprudencia derivada de amparos indirectos en revisión en la que se declare la inconstitucionalidad de una norma general..."

Agotado lo anterior, el segundo requisito para la procedencia del ejercicio de la declaratoria general de inconstitucionalidad es que el Pleno de la Corte hubiere notificado al órgano emisor de la norma y éste no hubiere procedido a la modificación o derogación de la misma dentro del término de 90 días naturales, ello en términos del segundo párrafo del artículo 232 de la Ley de Amparo, veamos:

Artículo 232, segundo
párrafo. - Una vez que
se hubiere notificado al
órgano emisor de la norma
y transcurrido el plazo de
90 días naturales sin que
se modifique o derogue
la norma declarada
inconstitucional, el pleno
de la Suprema Corte de
Justiciadela Nación emitirá
la declaratoria general

de inconstitucionalidad correspondiente siempre que hubiera sido aprobada por mayoría de cuando menos ocho votos.

Para efectos de la procedencia de la notificación "preliminar" de los 90 días, no es necesario mayor trámite ante la Suprema Corte, sino que es suficiente la mera existencia de la jurisprudencia que declare la inconstitucionalidad de un precepto legal.

Así, una vez agotados los pasos señalados en los anteriores incisos, el Pleno del Máximo Tribunal deberá determinar si se declara la inconstitucionalidad de la norma correspondiente con efectos generales. Es hasta aquí cuando se ejerce la facultad de control en abstracto de la norma cuestionada, lo es en abstracto toda vez que, a diferencia del juicio de amparo, no se estudia a la luz de un acto concreto de aplicación, sino que se efectúa un análisis en abstracto de la norma; esto tiene sentido si se toma en consideración que las jurisprudencias en las que se determina la inconstitucionalidad de una norma general derivan del estudio de un acto concreto y que, por esa razón, su inconstitucionalidad es determinada a la luz de un solo supuesto, por lo que no es factible sujetar el estudio que la Corte realice en una declaratoria general de inconstitucionalidad a los casos que en concreto fueron analizados por los amparos que dieron origen a la jurisprudencia correspondiente.

De acuerdo con esto, se demuestra que la declaratoria general de inconstitucionalidad no afecta de modo alguno las situaciones 
que en concreto se hubieren analizado y resuelto dentro de un amparo indirecto en revisión y, además, efectúa un estudio diverso al que se realiza al resolverse sobre la inconstitucionalidad de normas indirectamente o mediante un acto concreto de aplicación.

Así, no es factible considerar que, de forma alguna, se ha afectado o modificado el denominado principio de relatividad del juicio de amparo, pues la declaratoria general no tiene como resultado otorgar efectos erga omnes (Cárdenas, 2013) a la inconstitucionalidad determinada en jurisprudencia por reiteración al resolverse juicios de amparo indirectos en revisión, pues se debe ver a esas jurisprudencias como precedentes que únicamente determinan que en un caso en específico es inaplicable una norma porque, de ser aplicada, se violarían principios constitucionales. De este modo, no es factible tomar una jurisprudencia que analiza la constitucionalidad de una norma general en un caso en específico y simplemente darle efectos generales, sino que es necesario hacer un nuevo análisis, pero ahora en abstracto, de la norma general cuestionada y así poder considerar su inconstitucionalidad, otorgándole entonces efectos generales.

Esta declaratoria únicamente procederá si la misma es aprobada con, cuando menos, ocho votos de los integrantes del Pleno, situación que guarda mucha semejanza con la acción de inconstitucionalidad, ya que, dentro de esta figura, igualmente, se requiere de cuando menos ocho votos para que la declaratoria de invalidez de una determinada norma sea procedente.
En relación a esto último, es menester ver que en la declaratoria general de inconstitucionalidad, la Suprema Corte de Justicia de la Nación únicamente efectuará la declaración de inconstitucionalidad teniendo como efecto la pérdida de vigencia de la misma y, del mismo modo, la prohibición de su aplicación hacia el futuro. La declaración será obligatoria para todas las autoridades del país siempre que la misma establezca la fecha a partir de la cual surtirá sus efectos (Herrera, 2015), los alcances y las condiciones de la declaratoria de inconstitucionalidad, y sea publicada en el Diario Oficial de la Federación en términos de los artículos 234 y 235 de la Ley de Amparo.

\section{DISCUSIÓN}

El Pleno de la Suprema Corte de Justicia de la Nación es la única instancia en la que podría admitirse una excepción a la fórmula Otero cuando se resuelve un amparo en revisión contra normas generales $\mathrm{y}$, de esta manera, solucionar los problemas que actualmente no permiten al juicio de amparo consolidarse como un medio de control constitucional perfecto.

A través de la reforma constitucional, y de las disposiciones adicionales que la reglamentan, la inconstitucionalidad de las normas jurídicas una vez declarada de manera general las hará prácticamente inaplicables, en beneficio de todos los gobernados, no solamente de aquéllos que interpusieron la demanda de amparo indirecto correspondiente, lo cual permite una impartición de justicia más justa, más económica y más expedita. 


\section{REFERENCIAS}

1. Burgoa, Ignacio. (1999). El juicio de amparo. México, Porrúa.

2. Cámara de Diputados. (2013). Ley de amparo, reglamentaria de los artículos 103 y 107 de la Constitución Política de los Estados Unidos Mexicanos. México.

3. Cárdenas, Jaime. (2013). La nueva Ley de Amparo. Cuestiones constitucionales, (29), 383-409

4. Diccionario jurídico. (2020). Principio de relatividad. Recuperado de: $\underline{\text { http:// }}$ www.diccionariojuridico.mx/definicion/principio-de-relatividad/

5. Fernández Fernández, Vicente \& Samaniego Behar, Nitza. (2011). El juicio de amparo: historia y futuro de la protección constitucional en México. Rev. IUS, 5(27), 173 200.

6. Fix-Zamudio, Héctor. (1993). Ensayos sobre el derecho de amparo. México, UNAM.

7. Herrera García, Alfonso. (2015). El objeto de protección del nuevo juicio de amparo mexicano. Revista Derecho del Estado, (34), 153-181. https://doi. org/10.18601/01229893.n34.08

8. Pleno. Novena Época. 1005115. 317. Apéndice 1917-septiembre 2011. Tomo II. Procesal Constitucional 2. Amparo contra leyes Primera Parte - SCJN Sexta Sección - Sentencias en amparo contra leyes y sus efectos, Pág. 3989.

9. Tribunales Colegiados de Circuito. 229155. Octava Época. Semanario Judicial de la Federación. Tomo III, Segunda Parte-2, enero-junio de 1989, Pág. 779. 